Review

\title{
Analysis of Barriers and the Potential for Exploration of Deconstruction Techniques in Portuguese Construction Sites
}

\author{
João Couto * and Armanda Couto \\ Department of Civil Engineering, University of Minho, 4800-058 Guimarães, Portugal; \\ E-Mail: amcouto@sapo.pt \\ * Author to whom correspondence should be addressed; E-Mail: jpc@ @ivil.uminho.pt; \\ Tel.: +351-2535-10200; Fax: +351-2535-10217.
}

Received: 1 December 2009 / Accepted: 22 January 2010 / Published: 27 January 2010

\begin{abstract}
Deconstructing a building is the careful dismantling of that building so as to make possible the recovery of construction materials and components, promoting their reuse and recycling. However, deconstruction remains a rare procedure in Portugal. Using previous studies and data collected from present experiences, this paper presents a critical discussion on the importance of deconstruction for rehabilitation. Its aims are to discuss the main advantages, barriers and opportunities of this demolition technique, as well as the guidelines to the design process, aiming at assuring a successful management deconstruction process. Suggestions to impel this technique in Portugal are also described.
\end{abstract}

Keywords: deconstruction; rehabilitation; waste management; reuse; construction sites

\section{Introduction}

There are presently over five million houses in Portugal. Three-and-a-half million are inhabited, one million are second or holiday homes, and half-a-million are empty. Yet, the construction industry is reluctant to adapt itself. From 1999 through to 2002, a total of 106,000 houses were built per year and municipal zoning plans anticipate, in the north region of the country alone, that there are enough houses for 15 million residents when the population is only about three-and-a-half million. Considering the population density, Portugal is the European country with most houses per resident and still it is the country where most homes are built. The 2001 census listed 5,019,425 buildings, 1,222,280 of which were built before 1960 and constitute about one fourth of the total [1]. 
There is, then, this enormous patrimony that is waiting to be rehabilitated, as many of these buildings are sorely in need of interventions. Paradoxically, very little rehabilitation takes place in our country-indeed, it is below 20 percent, whereas in other European countries it raises to about 45 percent. The lack of interest in rehabilitation underpins behaviours that do not allow for sustainability in the construction sector. The attitude is partly connected to the fact that building rehabilitation involves knowledge of building materials and techniques that have been superseded. More often than not, the rehabilitation of a building will stop at the preservation or restoration of the facade, disregarding the reuse of the materials inside, even though in some cases they can be recovered and employed in the new intervention.

The building activity at Portuguese city centres tends to be an important waste generator because both refurbishment projects and new projects often include demolition [2]. Surveys conducted in several countries found that the amount of waste generated by the construction and demolition activity is as high as 20-30 percent of the total waste entering landfills throughout the world and the weight of the generated demolition waste is more than twice the weight of the generated construction waste [3]. Other studies compared new construction with refurbishment, and concluded that the latter accounts with more than 80 percent of the total amount of waste produced by construction activity as a whole.

No-holds-barred demolition produces an enormous quantity of debris which will, in most cases, only add to the pile of material to be used for landfills. Due to community concerns over potential impacts on the environment in developed areas, it is becoming more and more difficult to have landfills at such sites. On the other hand, having landfills in areas further away from human activity increases transport and power costs. An alternative to packing off these materials and constructive materials to a landfill is to choose deconstruction over the more common habit of demolition.

Deconstruction is the process of taking a building or structure apart, selectively dismantling and removing materials before the structure is demolished, or avoiding demolition altogether and disassembling the entire structure, in the reverse order to that in which it was constructed [4]. It is a concept that emerged due to the rapid increase of demolitions and growing environmental concerns expressed throughout society. Yet, deconstruction processes are still perceived as an interesting way to cut down on the production of debris, but one that fails to garner general understanding and acceptance. For this to come about, environmental rules and regulations must be promoted. Deconstruction needs to be developed and promoted. We need to raise awareness about the importance of deconstruction with the parties involved in the construction industry, especially owners, project designers and contractors [5].

\section{Deconstruction: A Tool in Building Rehabilitation}

In Portugal, often enough, in order to rehabilitate a building, some of its elements are demolished and little or no reuse of materials and constructive elements is done because selective demolition is not usual.

Rehabilitation and deconstruction are concepts that fit the overall framework of sustainability in construction, as they both focus on the valuation of existing resources. There can be two sides to rehabilitation, whether talking about general-purpose contemporary buildings or those that constitute cultural and historic patrimony. In the first case, the RICS (Royal Institution of Chartered Surveyors) 
concept may be adopted. Rehabilitation is: the extensive repair, renovation and modification of a building to have it suit economic or functional criteria equivalent to those expected of a new building that serves the same purpose. It may involve putting in place installations and service systems, means of access, natural lighting, equipment and finishes, using but the bare bones of the old building [1].

The rehabilitation of buildings clearly dovetails with the concept of sustainable development. By valuing the recovery of existing buildings, the need for new construction is diminished. As a consequence, urban sprawl has less impact on surrounding areas whose environmental, ecological and agricultural value is often considerable. Deconstruction paves the way for the revaluation and reuse of construction materials and elements which would otherwise be treated as worthless debris and removed to storage spaces which are often not legally authorized to hold such materials. Furthermore, by valuing construction materials and elements, procurement of raw material is diminished, as well as the need to process and transport raw materials. The need to manufacture new components and products is also lessened, which has economic and environmental advantages [6,7].

\section{Barriers and Advantages of Deconstruction}

\subsection{Barriers and Opportunities for Deconstruction}

There are a number of areas where the authorities may influence design and planning strategies at an early stage. These include fiscal incentives such as the maintenance of a fixed price for recovered products or increased costs for waste disposal through the landfill tax. Incorporation of deconstruction techniques into material specifications and design codes on both a National and European level would focus the minds of designers and manufacturers. Education of the long-term benefits of deconstruction techniques for regulators and major clients would provide the necessary incentive for the initial feasibility stage. Design for deconstruction is not, however, solely an issue for the designers of buildings. The development of suitable tools for the safe and economic removal of structural elements is an essential pre-requisite of the more widespread adoption of deconstruction [8].

A recent study by BRE (Building Research Establishment) has shown what the industry has known for decades; that there are keys factors that affect the choice of the demolition method and particular barriers to reuse and recycling of components and materials of the structures. Most factors are physical in terms of the nature and design of the building, along with external factors such as time and safety. Future factors to consider should also include the fate of the components, the culture of the demolition contractor and the 'true cost' of the process. For the latter, barriers to uptake include the perception of planners and developers, time and money, availability of quality information about the structure, prohibitively expensive health and safety measures, infrastructure, markets quality of components, codes and standards, location, client perception and risk.

According Hurley and Hobbs [9] the main barriers in the UK to the increased use of deconstruction methods within construction include:

- Lack of information, skills and tools on how to both deconstruct and design for deconstruction.

- Lack of a large enough established market for deconstructed products. 
- Lack of design. Products are not designed with deconstruction in mind.

- Reluctance of manufactures, which always prefer to purchase a new product rather than to reuse an existing one.

- Composite products. Many modern products are composites which can lead to contamination if not properly deconstructed or handled.

- Joints between components are often designed to be hidden (and therefore inaccessible) and permanent.

Even though there are significant advantages to deconstruction as an option for building removal, there are still more challenges faced by this alternative:

- Deconstruction requires additional time. Time constraints and financial pressure to clear the site quickly, due to lost time resulting from delays in getting a demolition, or removal permit, may detract from the viability of deconstruction as a business alternative.

- Deconstruction is a labor-intensive effort, using standard hand tools in the majority of cases. Specialized tools designed for deconstructing buildings often do not exist.

- The proper removal of asbestos-containing materials and lead-based paints, often encountered in older buildings that are candidates for deconstruction, requires special training, handling, and equipment.

- Re-certification of used materials is not always possible, and building codes often do not address the reuse of building components.

The main opportunities which require development include:

- The design of joints to facilitate deconstruction.

- The development of methodologies to assess, test and certify deconstructed elements for strength and durability, etc.

- The development of techniques for reusing such elements.

- The identification of demonstration projects to illustrate the potential of the different methods.

The greatest benefit will be achieved by incorporating deconstruction issues into the design and feasibility stage for all new construction. Each case can then be judged on its merits in terms of the potential cost of recovery and recycling or reclamation and reuse of construction materials.

\subsection{Deconstruction Benefits}

The benefits from deconstruction are significant. Deconstruction offers historical, social, economic and environmental benefits. Older buildings often contain craftsmanship of significant historical value. Deconstruction can carefully salvage these important historical architectural features because materials are preserved during removal. Deconstruction is more time consuming and requires more skill than simply demolishing a structure. Although the extra time required could act as a detriment, the additional jobs that can be created benefit the community. Deconstruction provides a market for labour and sales of salvaged material. More important, deconstruction puts back into circulation items which may be directly used in other building applications, reducing the amount of waste sent to landfills. Currently there are few incentives to break the historical practice of landfilling debris. The 
occasionally higher cost of selected demolition can be offset by the increased income from salvaged materials, decreased disposal costs, and decreased costs from avoided time and expense needed to bring heavy equipment to a job site [8].

Building deconstruction supports the waste management hierarchy in its sequence of preferred options for the management of generated C\&D waste materials (See Figure 1). If a building is still structurally sound, durable and flexible enough to be adapted for a different use (either in situ or by relocation), then waste can be reduced by reusing the whole building. If components and materials of a building can be recovered in high quality condition, then they can be reused. If the building materials are not immediately reusable, they can be used as secondary feedstock in the manufacture of other products, i.e., recycled. The aim is to ensure that the amount of waste that is destined for landfill is reduced to an absolute minimum. This approach closes the loop in material flow thereby contributing to resource efficiency.

Figure 1. Waste Management and End-of-life Scenario Hierarchies for demolition and construction operations. Source: adopted directly from [10].

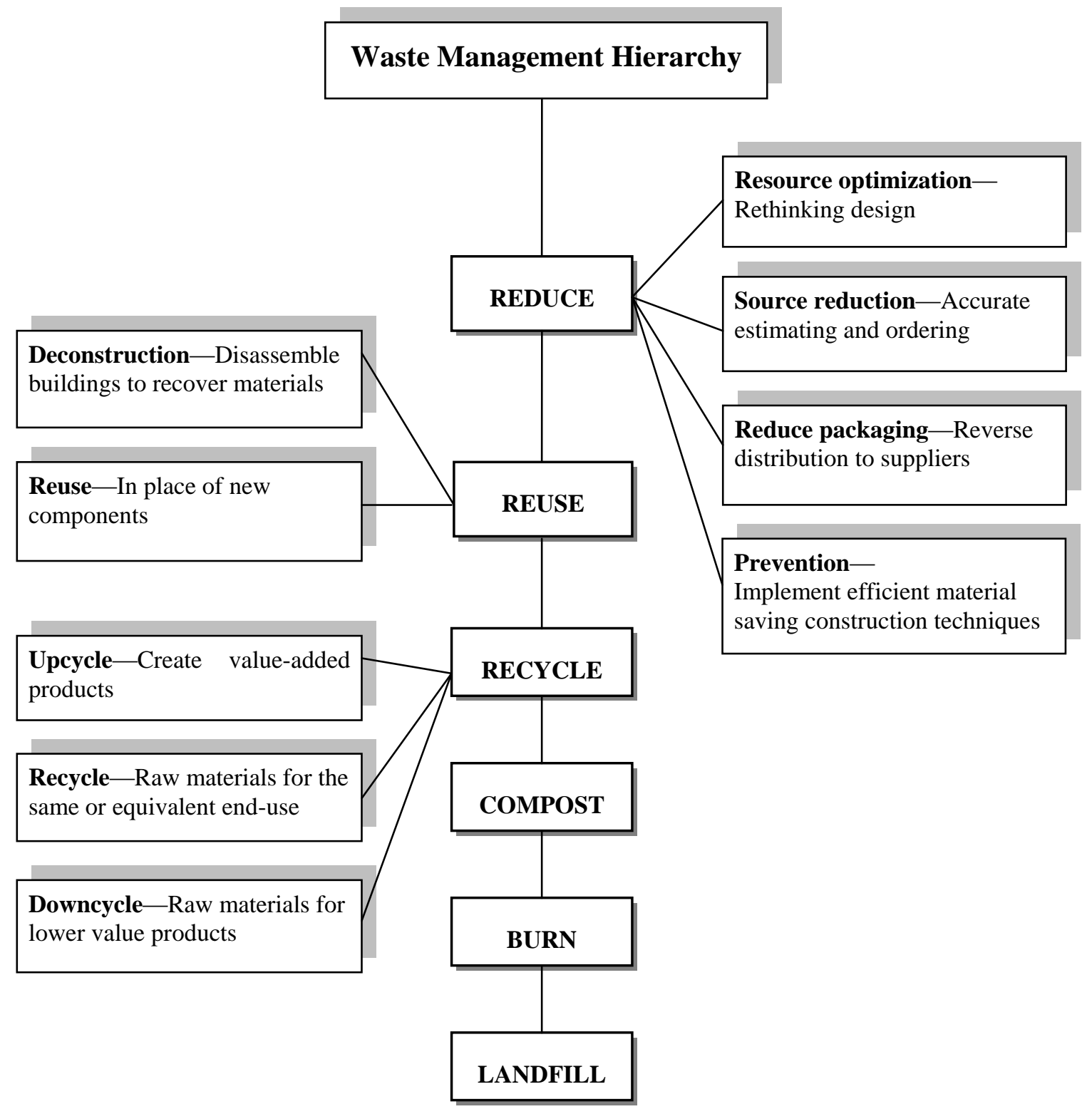


To ignore deconstruction means to create a pile of debris that cannot be viably reused. The following figure attempts to depict this situation; to demolish a build without resorting to procedures that enable separation and recovery of debris and by-products.

Figure 2. Sample of undifferentiated demolition. Source: [11].

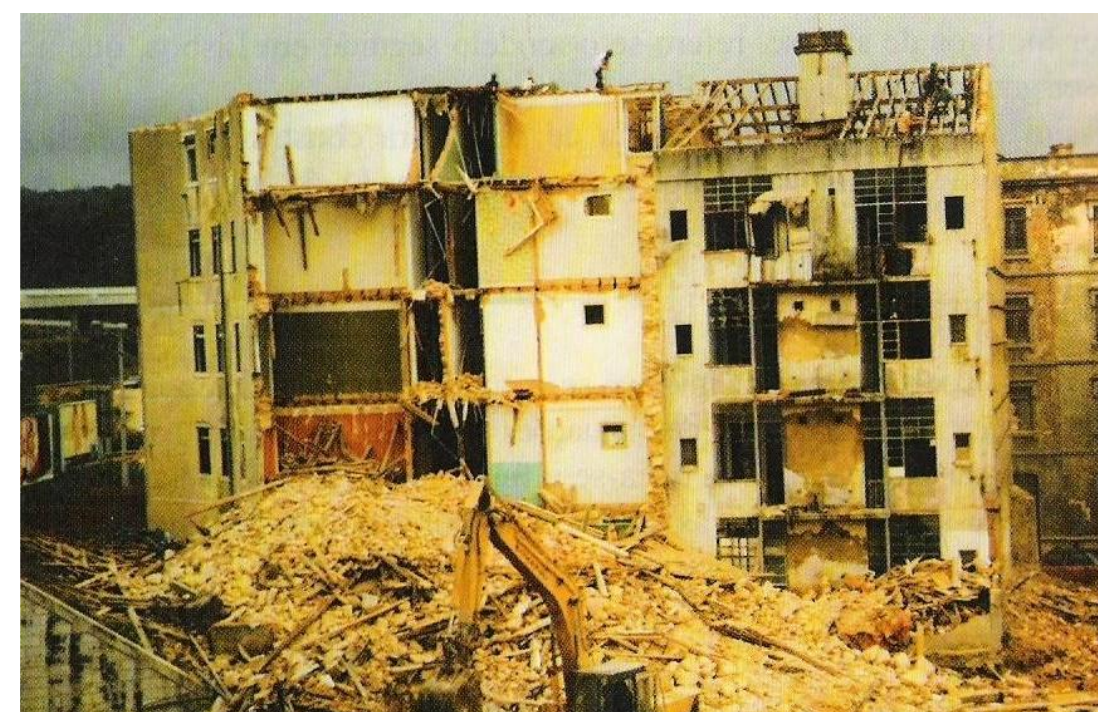

The Figure 3 attempts to depict that deconstruction permits the resorting procedures that enable separation and recovery of debris and by-products.

Figure 3. Sorted broken concrete and steel stockpiled separately [12].

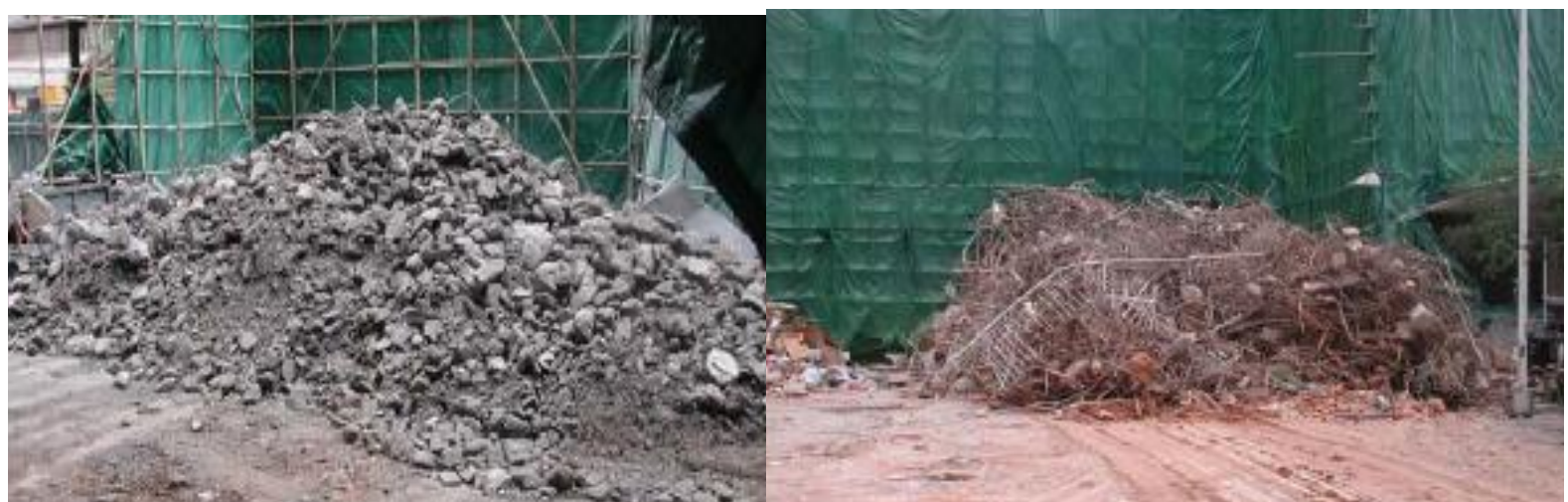

In summary, deconstruction allows to:

- Reuse and recycle materials: materials salvaged in a deconstruction project can be reused, remanufactured or recycled (turning damaged wood into mulch or mortar and concrete into aggregate for new foundations) [4].

- Foster the growth of a new market - used materials: recovered materials can be sold to a salving company. The market value for salvaged materials from deconstruction is greater than from demolition due to the care that is taken in removing the materials in the deconstruction process.

- Environmental benefits: salvaging materials through deconstruction helps reducing the burden on landfills, which have already reached their capacity in many localities. By focusing on the 
reuse and recycling of existing materials, deconstruction preserves the invested energy embodied in materials, eliminating the need to expend additional energy to process new materials. By reducing the use of new materials, deconstruction also helps reducing the environmental effects, such as air, water and ground pollution resulting from the processes of extracting the raw materials used in those new construction materials. Deconstruction results in much less damage to the local site, including soil and vegetation, and generates less dust and noise than demolition.

- Create jobs: deconstruction is a labour-intensive process, involving a significant amount of work, removing materials that can be salvaged, taking apart buildings, and preparing, sorting, and hauling the salvaged materials.

\subsection{Cost of Deconstruction}

Deconstruction, as an environmentally-sound business practice, is not necessarily more costly than traditional demolition. Buildings can be often be deconstructed more cost-efficiently than they can be demolished. There are many different factors involved, including the type of construction and the value of the materials that can be recovered. But overall, deconstruction can be more cost-effective than demolition. Preliminary results from pilot projects carried out in different parts of the USA by US Environmental Protection Agency (EPA) have indicated that deconstruction may cost $30 \%$ to $50 \%$ less than demolition [13].

Deconstruction is labor-intensive, involving a higher level of manual work than there would be in a demolition project. But the higher labor cost can be offset by lower costs for equipment rent and energy usage, cost savings in the form of lower transportation and landfill tipping charges, and the revenues from sales of the salvaged material.

Research shows that the market value for salvaged material is greater when deconstruction occurs instead of demolition, because of the care taken in removing materials. Money made through salvaging can be used to offset other redevelopment costs. Lastly, disposal costs are lower with deconstruction because the process reduces the amount of waste produced by up to 75 percent [13].

According to Laefer and Manke [14] the main benefits of building reuse include sustainability, direct (labor expenditures, material expenses and disposal costs) and indirect monetary savings, an accelerated construction schedule, and decreased liability exposure. As each construction project has its own specific requirements, reuse is not always the most economical solution, but in cases where reuse is partly motivated by other factors such as heritage protection, substantial economic and environmental savings can be coordinated.

\section{Guidelines to Design for Deconstruction and Tools to Materials Recovery Analyses}

The recognition that building design must enable the future reuse and recycling of building elements has been growing. Buildings that can be dismantled and the elements reused or recycled are effectively a source of building materials. The use of such reclaimed and recycled materials avoids the need to resource virgin materials, which, in turn, reduces the associated environmental impacts. As a rule, materials should be extracted from buildings and reintegrated directly or reprocessed and then 
reintegrated into buildings or put to useful purpose in other sectors without creating any waste. This concept is referred to as closed-loop cycle (CLC) materials. The concept of closed-loop material cycles (CLMCs) combines the aims of 'zero waste' and resource-efficient construction [15]. Thus, a waste reduction through the creation of material flow closed-loop will have an important role in getting a more sustainable construction.

The chance of recovery of materials depends on the technique of deconstruction applied at the end of a building's life. For the evaluation of the environmental impact of product recovery, a measure called energy-savings value (ESV) that is based on life cycle energy analysis (LCEA) was developed by Schultmann [16]. This measure allows a comparison of the use of recovered components and building materials with the production of components and building materials from primary resources. Thus, based on a life cycle energy analysis, recovery options can be selected for deconstructed components and materials such that the best possible environmental and economic benefit in terms of energy savings is achieved.

Designing for Deconstruction (DfD) is an emerging concept that considers the whole life cycle of a building, from initial design through eventual removal, incorporating aspects of disassembly, recycling, and reverse manufacturing.

The benefits of deconstruction can be greater if during building design some issues are taken into account [17]:

The strategies suggested for material recycling are:

- To use recycled materials - the incremented usage of recycled materials will encourage both industry and governments to investigate new recycling technologies and the creation of a greater support network for future recycling and reuse.

- To minimize the number of different types of material-this will simplify the material organization process and reduce transportation.

- To avoid toxic or potentially harmful materials - this will lessen the contamination potential inherent to materials segregated and will also reduce potential risks to human health during disassembly.

- To schedule separate assembly of materials with different reuse potential - this will keep large quantities of a given material from being contaminated by small quantities of another that cannot be separated.

- To avoid secondary finishing and coating whenever possible-these materials may contaminate the underlying material and make recycling less workable. Whenever possible, use of materials that incorporate their own surface coating or finish or use of separate mechanically connected finishing.

- To provide permanent identification of types of material - many substances, such as plastics, are not easily identified and should have ID tags or marks signalling 'non-removable' or 'non-contaminant' so as to make them easier to organize in the future.

According to Crowther [17,18] there are four possible recovery scenarios for recovery of materials (see Figure 4), which are presented hierarchically. Reuse is preferred over reprocessing or recycling. 
Figure 4. Scenarios for recovery of materials in a construction environment. Source: $[17,18]$.

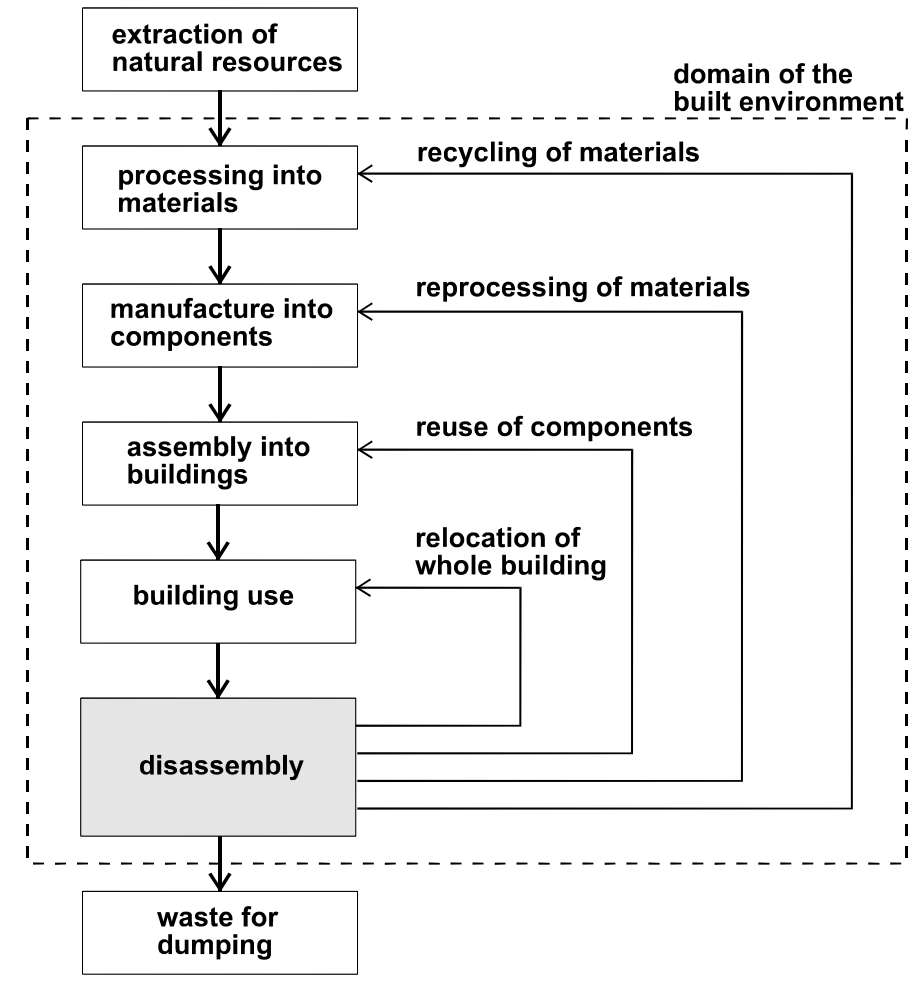

The strategies suggested for component reprocessing are:

- To minimize the number of different types of components - this will simplify the process of sorting on site and make the potential for reprocess more attractive due to the larger quantities of same or similar items.

- To use a minimum number of wearing parts - this will reduce the number of parts that need to be removed in the remanufacturing process and thereby make reprocessing more efficient.

- To use mechanical connections rather than chemical ones-this will allow for the easy separation of components and materials without force, and reduce contamination to materials and damage to components.

- To make chemical bonds weaker than the parts being connected - if chemical bonds are used, they should be weaker than the components so that the bonds will break during disassembly rather than the components; for example, mortar should be significantly weaker than the bricks.

The strategies suggested for component reuse are:

- To choose an 'open space' construction system that allows for changes in the compartmentalization of the building through replacement of components without significant construction work.

- To use assembly technologies that are compatible with standard building practices - resorting to specific technologies will make disassembly harder and may call for special labour and equipment, turning this into a less attractive option. 
- To separate the structure of inner walls from casements or coatings - so as to allow for parallel disassembly, where some parts of the building may be removed without affecting others.

- To provide access to all parts of the building and to all components - ease of access will favour disassembly. Whenever possible, to allow that component recovery inside the building is made without specialized equipment.

- To use components that make handling easier-allowing for handling at every stage; disassembly, transportation, reprocessing and reassembly.

- To consider the space involved and the means necessary to deal with the many components during disassembly-handling may call for connection points for lifting equipment or temporary support or buttressing mechanisms.

- To ensure realistic slack among elements so as to allow for all the necessary movements during disassembly.

- To use the smallest possible diversity of connectors-enforcing standards will make disassembly easier, faster, and demand fewer kinds of tools and equipment. Even if the end result is oversized connections, the time required for assembly-disassembly will surely be enough compensation.

- To use a disassembly hierarchy connected with the components' lifespan - using components with shorter life spans where access and disassembly are easier.

- To provide for permanent identification of component types - using international-standard barcodes may make it easier to divulge deposit banks and the commercialization of materials and components found in different places.

Design for deconstruction guidelines for building adaptability or relocation are:

- To standardize the parts while allowing for an infinite variety of the whole - this will allow minor alterations to the building without major building works.

- To use a standard structural grid - grid sizes should be related to the materials used such that structural spans are designed to make most efficient use of material type.

- To use a minimum number of different types of components-fewer types of component means fewer different disassembly operations that need to be known, learned or remembered - it also means more standardization in the reassembly process which will make the option of relocation more attractive.

- To use lightweight materials and components - this will make handling easier, quicker, and less costly, thereby making reuse a more attractive option.

- Permanently identify point of disassembly_points of disassembly should be clearly identifiable and not be confused with other design features.

- To provide spare parts and on site storage for them (especially for custom built components) - both to replace damaged components and to facilitate minor alterations to the building.

- To sustain all information on the building manufacture and assembly process-measures should be taken to ensure the preservation of information such as 'as built drawing', 
information about disassembly process, material and component life expectancy, and maintenance requirements.

\section{Contribution towards Increased Competitiveness of Companies}

As is generally known, the competitiveness of the construction sector relies on the entrepreneurial capabilities of its companies, which goal is to provide a quality, innovative service. This work aims at foregrounding knowledge in the fields of rehabilitation and reconstruction, giving companies an edge as far as deconstruction techniques are concerned. These techniques are preferable to undifferentiated demolition and meet legislative demands on materials' reuse and recycling, which construction companies do not yet pay much attention to. The pre-project on construction and demolition by-products and debris proposes implementation of debris and by-product management plans at the project design stage. This seems to be a correct, effective way to foreground the importance of debris management and to get all participants involved, beginning with the design stage and going all the way through to implementation.

The plan specifications contemplate an estimate for the debris and by-products resulting from the construction work. It then becomes necessary, at the design stage, to be more and more aware of the debris that will be produced. Adequate logging and shipping are also considered in this legislative document. These attitudes indicate the path to follow.

It is very likely that, in the near future, much as is happening all over Europe now, new technologies for material reuse and recycling will be chosen over old habits. We hope this work will bring knowledge to companies that helps them to adopt environmentally sound attitudes; they will not only benefit economically but also in terms of their public image. Environmentally sound positions are a great promotional tool, especially if you consider the many problems the world is going through right now that can be chalked up to our thinking in exclusively economic terms.

\section{Establishing a Conduct for a Successful Deconstruction Process}

Advanced planning for deconstruction or salvage before demolition is crucial for its success. The first step is to assess the deconstruction potential [2]:

- Conduct a walk-through with the owner's representative and a deconstruction contractor to determine the feasibility and level of salvage possible. Identify materials and job phases where recovery, recycling and salvage opportunities are the greatest. The walk-through also can identify materials that could be salvaged and reused on-site.

- To compare costs, require estimates for full deconstruction of the structure, targeted salvage prior to demolition, and traditional demolition.

- Based on the walk-through and cost comparison, it should be determined if full deconstruction of the structure is an option or if salvage prior to demolition would be more effective.

After that, one should be establish goals for deconstruction salvage and recycling and include these goals in the specifications. 
Based on the walk-through, a list of materials to be salvaged should be developed. Identify materials to be reused on-site. For materials that will be sold or donated off-site, salvage companies that accept reused building materials should be contacted. It is important to use specification language in the construction waste management specifications to address deconstruction or salvage prior to demolition. The language should include goals or measurable standards for the level of salvage and/or a list of materials to be salvaged.

Deconstruction and salvage prior to demolition are usually more time-consuming than traditional demolition. It is important that sufficient time is allowed to dismantle the building or to salvage reusable items before demolition. For that, it is recommendable to take the following measures:

- Determine in advance how much time is available to complete the demolition phase of the project. The bid and contract process is the best place to assure that adequate time is available. Contracting mechanisms include decoupling demolition from the design/build phase of construction contracts. The demolition aspect of the project can be delayed while the terms of the larger design/build agreement are worked out, thus allowing time for deconstruction and salvage prior to completing demolition.

- Other alternatives to ensure enough time to complete deconstruction and salvage include issuing an early notice to proceed for the demolition phase of the project or creating a separate request for proposal or bid and contract for deconstruction and demolition.

It also is important for the architect to identify and remove barriers to salvage and reuse by eliminating language in contracts that prohibit rather than control activities such as on-site salvage, storage of salvaged materials, or processing operations that might create noise pollution like on-site concrete crushing. The contractor is required to develop a reuse and salvage plan as part of the waste management plan for the project by including this requirement in the specification language. The reuse and salvage plan should include a list of items being reused in place or elsewhere on-site; a list of items for reuse off-site through salvage, resale or donation; a plan for protecting, dismantling, handling, storing and transporting the reused items; and a communications plan describing the salvage plan to all players.

Finally, the contractor should be also required to provide clear and consistent communication at the job site to be sure the crew is informed of the salvage plans, procedures and expectations. Careful removal and handling of the reuse and salvage materials is crucial to their usability and marketability - the key to success is communicating the priorities, making detailed plans and carefully monitoring the progress to insure success.

\section{Suggestions to Impel the Deconstruction Process in Portugal}

In Portugal the construction sector is still very traditional, so new practices and attitudes are difficult to implement [19]. New challenges like refurbishment and waste management have been systematically postponed. In order to improve the construction waste management by impelling the deconstruction process it will be necessary to implement some few strategic actions: 
- To approve specific legislation.

- To improve the efficiency of the authority control.

- Training all construction intervenients.

- Diffusion of benefits by workshops.

- To consider environmental factors in contractors selection.

- To increase the disposal taxes.

- To increase the penalties for the illegal landfills.

\section{Final Comments}

The Portuguese construction industry is going through a process for the implementation of quality programs. This will surely contribute towards the reduction of debris and by-products created by the sector. However, the amount of debris will not be reduced overnight. Furthermore, no matter how effective the changes made to constructive processes are with the aim of cutting the costs and debris generated, there will always be debris and this, added to the demolition ones, still represents an excessive volume of debris. On the other hand, due to the need for adaptation and improvement of existing buildings, taking into account the new standards of quality and comfort, the works involving demolition of buildings or parts of buildings are becoming increasingly frequent in Portugal.

Thus, the study of practical solutions that point to the reuse of building materials and components, will contribute to a decrease in the urban problem created by illegal landfills — bringing environmental improvement - and will introduce new materials into the market which have potential for use. The deconstruction process appears as an adequate answer for these challenges and with a significant potential for exploitation in Portuguese building refurbishment. In this sense, it is very important to make the effort to overcome the barriers to the increased use of deconstruction methods as an option for building removal.

The production of legal documents that encourages more environmentally positive behaviour, that is, that arouse and force the construction industry to handle its debris and by-products more carefully, is of vital importance to the contribution of this sector for sustainable development, to which all must contribute. In this context, special mention must be made of the mandatory waste management plan in public projects, which must be incorporated during the design stage. It seems to be a correct and effective way to highlight the importance of waste management and to get all the participants involved, from the design to the construction stage. This change, however, must be accompanied by public awareness campaigns. It is not enough to stress that the plan is mandatory. The plan's importance must be addressed too. It will be easier to reach our goals if all know the advantages and importance of such a plan.

\section{References and Notes}

1. Entrepreneurs Council for Sustainable Development. Rehabilitation: The Best Away for Sustainable Construction; Available online: http://www.bcsdportugal.org (accessed on 15 September 2006). 
2. Couto, J.P.; Couto, A. Strategies to improve waste management in Portuguese construction industry: The deconstruction process. Int. J. Environ. Waste Manage. 2009, 3, 164-176.

3. Bossink, B.G.; Brouwers, H.J. Construction waste: Quantification and source evaluation. J. Construct. Eng. Manag. 1996, 122, 55-60.

4. Hagen, K. Deconstruction as an Alternative to Demolition-Helping the Environment, Creating Jobs, and Saving Resources; Available online: http://www.associatedcontent.com (accessed on 23 September 2008).

5. Chunlu, L.; Pun, S.K.; Itoh, Y. Technical development for deconstruction management. In Proceedings of the CIB Conference on Deconstruction and Material Reuse, Gainesville, FL, USA, 7-10 May 2003.

6. Couto, A. Environmental Impact of Construction Sites in Historic Cities Centres; MSc Thesis; University of Minho: Guimarães, Portugal, 2002.

7. Couto, A.; Couto, J.P. Desconstrução-uma ferramenta para a sustentabilidade da construção. In Proceedings of the NUTAU'2006 Technological Innovation-Sustainability, VI Brazilian Seminary of Design Management Process in Building Projects, Sao Paulo, Brazil, 9-13 October 2006.

8. Couto, A.; Couto, J.P. Why deconstruction is not adequately considered in Portuguese building refurbishment. In Proceedings of the ARCOM 2007: 23rd ARCOM Annual Conference, Belfast, Northern Ireland, 3-5 September 2007.

9. Hurley, J.; Hobbs, G. Report 9: TG39-UK Country Report on Deconstruction; CIB Publication: Rotterdam, The Netherlands, 2004.

10. Kibert, C.; Chini, A. Deconstruction as an essential component of sustainable construction. In Proceedings of CIB Conference on Overview of Deconstruction in Selected Countries, University of Florida, Gainesville, FL, USA, 18-19 May 2000; pp. 6-14.

11. Pinto, F. Paredes de Edifícios Antigos em Portugal; National Laboratory for Civil Engineering (NLCE): Lisbon, Portugal, 2000.

12. Public Fill Committee-Civil Engineering and Development. Guidelines for Selective Demolition and on Site Sorting; The Government of the Hong Kong Special Administrative Region: Hong Kong, China, 2004.

13. Deconstruction Training Manual: Waste Management Reuse and Recycling at Mather Field; California Environmental Protection Agency: Sacramento, CA, USA, 2001.

14. Laefer, D.F.; Manke, J.P. Building reuse assessment for sustainable urban reconstruction. $J$. Construct. Eng. Manag. 2008, 134, 217-227.

15. Sassi, P. Defining closed-loop material cycle construction. Build. Res. Inform. 2008, 36, 509-519.

16. Schultmann, F.; Sunke, N. Energy-oriented deconstruction and recovery planning. Build. Res. Inform. 2007, 35, 602-615.

17. Crowther, P. Building deconstruction in Australia. In Proceedings of CIB Conference on Overview of Deconstruction in Selected Countries, University of Florida, Gainesville, FL, USA, 18-19 May 2000; pp. 14-44. 
18. Crowther, P. Developing an inclusive model for design for deconstruction. In Deconstruction and Materials Reuse: Technology, Economics and Policy, Proceedings of CIB Task Group 39 Meeting, Wellington, New Zealand, 6 April 2001; Chini, A., Ed.; CIB Publication: Rotterdam, The Netherlands, 2001; pp. 1-26.

19. Couto, A.; Couto, J.P. Prevenção de Impactos dos Estaleiros de Construção em Centros Históricos Urbanos; Publindústria: Oporto, Portugal, 2008.

(C) 2010 by the authors; licensee Molecular Diversity Preservation International, Basel, Switzerland. This article is an open-access article distributed under the terms and conditions of the Creative Commons Attribution license (http://creativecommons.org/licenses/by/3.0/). 